\title{
IbM Kelompok Petani Tebu Rakyat di Kecamatan Semboro, Kabupaten Jember
}

\author{
Ummi Sholikhah, Imam Sholahuddin \\ Staf Pengajar Program Studi Agrotekhnologi Fakultas Pertanian, Universitas Jember. \\ Staf Pangajar Fakultas Teknik (Mesin), Universitas Jember \\ Email: sholikhah_ummi@yahoo.com
}

\begin{abstract}
Sub-district Semboro is a strategic region for the development of sugarcane Agricultural commodities. According to the Central Bureau of Statistics Jember in 2008, the area under sugarcane cultivation in the district Semboro in 2008 approximately 491 acres, in the District Semboro also contained relatively large sugar mills and has the ability milling capacity of 70 thousand quintals or 7000 TCD ( Tones Cine Day ) with the extensive area of sugarcane commodities land, the availability of seed cane is also needed single bud planting method that is one of the breakthrough to overcome the problems in the nursery. In principle, a single bud planting method is to use a chip nursery development / potray with the buds. This can save planting materials, land and time in the nursery and produce quality seeds.

In the early stages of implementation IbM activities that began in April 2014 until now is still running smoothly without significant obstacles, so that every transfer of science and technology that is given to the partners can be accepted and implemented, plan future activities are the stages of the transfer of seed cane single bud results in PII in moving to production fields, and will be doing the evaluation of any activity undertaken.
\end{abstract}

Keywords: IbM, Semboro, Single Bud Planting

\section{PENDAHULUAN}

Kecamatan Semboro adalah salah satu Kecamatan di Kabupaten Jember yang terdiri dari 6 desa yaitu Rejoagung, Semboro, Sidomekar, Sidomulyo, Pondokjoyo, Pondokdalem. Kecamatan Semboro terletak di bagian barat dan Kabupaten Jember dengan jarak 35,5 kilometer dari lbukota Kabupaten. Secara geografis kecamatan Semboro terletak pada ketinggian 25 meter di atas permukaan laut, dengan luas wilayah 6,73 km2, dengan luas areal persawahan sekitar 2.607.8 hektar. Jumlah penduduk di Kecamatan Semboro sebanyak 43,805 jiwa dengan kepadatan pendudukk rata-rata
1.113,7 jiwa/ km2, sebagian besar penduduk bekerja di sektor pertanian. Sedangkan yang lain bekerja di sektor industri, perdagangan, jasa dll.

Kecamatan Semboro merupakan wilayah strategis untuk pengembangan Pertanian dengan komoditas tebu. Menurut Badan Pusat Statistik Jember tahun 2008, luas areal budidaya tebu di Kecamatan Semboro pada tahun 2008 sekitar 491 hektar, di Kecamatan semboro juga terdapat Pabrik Gula yang relatif besar dan mempunyai kemampuan kapasitas giling 70 ribu kwintal atau 7000 TCD (Ton Cine Day) dengan luas nya areal lahan dengan komoditas tebu maka kebutuhan akan 
ketersediaan bibit tebu juga sangat di butuhkan.

Petani di wilayah Kecamatan Semboro dan sekitar nya dalam menyediakan atau memgembangkan pembibitan tebu masih menggunakan metodekovensional yaitu dengan Stek batang atau bagal yang berasal dari batang tebu yang matanya belum berkecambah terdiri atas bagal mata satu, dua dan tiga, Metode Lonjoran Bagal dalam bentuk lonjoran dengan panjang 1,25 $\mathrm{m}$ terdiri atas 6 - 8 mata, Metode Rayungan berasal dari pangkasan batang tebu yang matanya telah tumbuh tunas bibit yang dihasilkan dapat terdiri dari satu tunas dan dua tunas rayungan yang telah tumbuh 5-7 daun (umur bibit 45 hari), metode Stek pucuk (Top Stek) yang berasal dari tebangan tebu giling yang varietasnya murni (dalam kondisi tidak ada bibit) dan untuk bahan sulam. Tebu giling pada saat tebang dalam kondisi sehat, tidak terbakar, murni dan bebas dari HPT. Metode konvensional tersebut memiliki beberapa kelemahan yaitu waktu pembibitan yang dibutuhkan lebih lama, serta membutuhkan lahan pembibitan yang luas dan bibit yang dihasilkan relative tidak seragam.

Untuk mengatasi permasalahan tersebut maka pembibitan tebu dengan metode single bud plantingmenjadi salah satu pemecahan masalah dalam pembibitan tebu. Pada prinsipnya metode single bud planting adalah pengembangan pembibitan menggunakan chip/potray dengan satu mata tunas dengan cara single bud planting maka Transplanting lebih cepat dan menerapkan jarak tanam lebar $(60 \mathrm{~cm})$, kondisi yang dibutuhkan agar pembibitan dapat berjalan dengan baik maka ketika tebu di pindah ke lahan kelembaban yang cukup perlu di jaga dan menghindari penggenangan air. Single bud Planting memiliki beberapa tujuan yang sangat penting yaitu:

a. Dapat Menghemat Kebun Pembibitan.

b. Bibit yang ditanam mempunyai keseragaman pertumbuhan.

c. Bibit yang perkecambahannya seragam mempunyai awal pertumbuhan yang sehat dan seragam d. Diharapkan hasil penangkaran bibit lebih banyak.

Metode Single Bud dalam memotong bagal yang akan di gunakan untuk bibit dapat dilakukan dengan cara manual yaitu dengan gergaji maupun dengan cara menggunakan mesin pemotong.

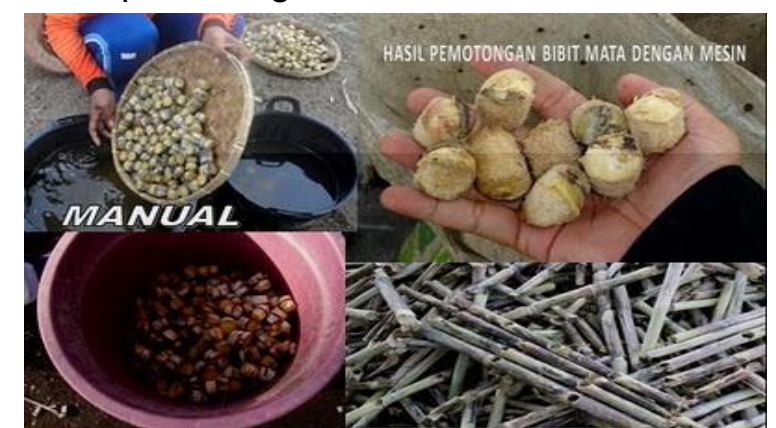

Gambar 1.1 Teknik pemotongan Bagal

Tebu bibit.

Pemotongan bahan tanam dengan cara manual dalam pemotongan bagal tentunya membutuh kan waktu yang relatif lama dan tenaga kerja yang lebih banyak. Berbeda dengan pengguanaan mesin pemotong mata tunas waktu yang di gunakan akan lebih cepat dan tenaga kerja lebih sedikit.

Setelah di peroleh bagal mata tunas satu maka proses selanjutnya adalah perlakuan water hot treatment yang kemudian dilanjutkan dengan penyemaian serta Pemindahan bibit ke dalam Potray.

Proses penyemaian hingga pemindahan bibit ke dalam potray kurang lebih membutuhkan waktu sekitar $1-1,5$ bulan.

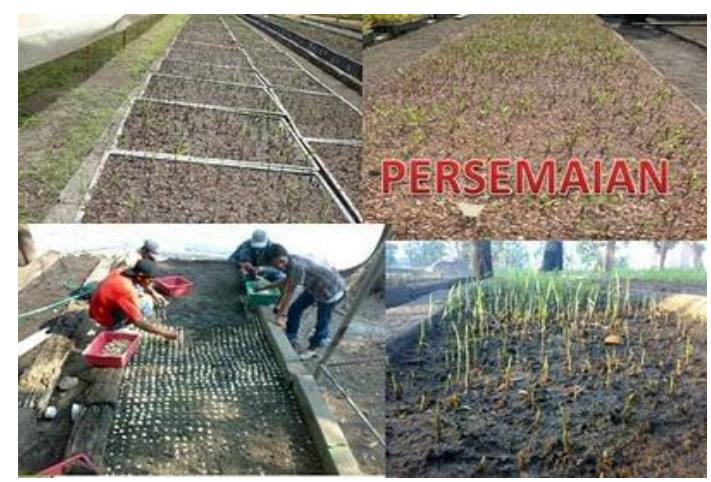

Gambar 1.2 Penyemaian Bagal ke dalam media Persemaian. 


\section{Permasalahan Mitra:}

Metode single bud planting adalah metode yang relatif baru di kembangkan di Indonesia pada umumnya dan di Kecamatan Semboro, Kabupaten Jember pada khususnya karena sebelumnya metode ini lebih banyak di gunakan di wilayah Colombia yaitu negara asala mula di gunakan metode single bud Planting. Setalah mengetahui analisis situasi di wilayah mitra berada maka dapat di ketahui beberapa permasalahan Mitra yang sekarang atau pada saat ini sedang di hadapi yaitu:

a. Kurangnya pengetahuan petani mengenai metode single bud planting.

b. Minimnya peralatan atau teknologi yang dimiliki oleh petani dalam pengembangan bibit single bud planting.

c. Minimnya pengetahuan petani mengenai pengembangan bisnis atau usaha pembibitan tebu dengan metode single bud planting dari sudut ekonomi atau tingkat keuntungan yang dapat di peroleh di bandingkan dengan metode konvensional, dengan mendapat kan pengetahuan ini harapannya dapat menambah pendapatan petani jika mereka mau mengambangkan metode single bud planting dalam usaha pembibitan tebu mereka.

\section{TARGET DAN LUARAN}

\section{Sisi Ekonomi}

a. Menghemat biaya produksi karena proses pembibitan yang relatif singkat.

b. Mengurangi kerugian karena daya tumbuh bibit yang relatif tinggi sehingga bibit yang di perlukan relatif sesuai dengan kebutuhan.

c. Meningkatkan kualitas dan kwantitas produksi bibit tebu yang di hasilkan

d. Meningkatkan pendapatan petani pengembang bibit maupun petani tebu

e. Membuka peluang pengetahuan pengembangan usaha pembibitan tebu dengan metode single bud planting.

f. Kebutuhan untuk pemenuhan ketersediaan bibit bagi petani tebu produksi masih sangant luas baik di sekitar Kecamatan semboro maupun di luar Kecamatan Semboro.

\section{Sisi IPTEKS}

a. Meningkatkan pengetahuan dan ketrampilan para petani tebu terkait dengan pengembangan bibit tebu dengan metode single bud planting.

b. Teknologi tepat guna yang barn sehingga dapat meningkatkan efisiensi produksi bibt tebu.

c. Menumbuhkan jiwa kewirausahaan yang mandiri guna mengurangi jurnlah pengangguran di Kecamatan Semboro maupun Kabupaten Jember.

d. Menjadi informasi dan komunikasi yang efektif bagi pihak-pihak yang berkepentingan dan peduli dengan pengembangan pembibitan tebu.

e. Merangsang pengembangan penelitian lebih lanjut dengan metode pembibitan tebu yang lebih modern.

\section{METODE PELAKSANAAN}

Kegiatan ini dilakukan dalam rangka untuk menyelesaikan masalah yang di hadapi oleh mitra dan mencapai tujuan yang telah di tetapkan.

Guna meningkatkan kualitas bibit tebu yang diperoleh maka akan dilakukan kegiatan - kegiatan dengan cara mensosialisasikan pengembangangan bibit tebu dengan metode single bud planting kemudian mengintroduksikan penggunaan alat pemotong tebu secara modern guna menghemat biaya dan tenaga kerja serta waktu yang digunakan lebih efisien dan efektif. Serta memberikan pengetahuan bagi petani tebu pengembang bibit tebu mengenai prospek pengembangan usaha pembibitan tebu dengan metode single bud palanting dari sudut pandang Ekonomi di bandingkan dengan metode konvensional.

Solusi yang di tawarkan dalam pelaksanaan kegiatan pengabdian ini terbagi dalam lima tahap pelaksanaan dengan sasaran adalah petani tebu pengembang bibit dan petani tebu produksi.

Kelima tahapan pelaksanaan pengabdian tersebut adalah: 
1. Alih teknologi pengetahuan cara pembibitan dengan metode single bud planting.

Pada tahap yang pertama dari kegiatan pengabdian ini dilakukan sosialisasi dan penyampaian informasi atau alih teknologi mengenai single bud planting baik kepada petani pengembang bibit maupun pada petani produksi. Disampaikan menganai cara-cara pelaksanaan terkait tahapan dari metode single bud planting, tujuan serta manfaat dari metode pembibitan ini. Banyak manfaat yang akan di peroleh jika pengembangan pembibitan single bud ini di laksanakan mulai dari waktu yang digunakan lebih singkat serta biaya yang relatif lebih murah serta kemungkinan daya tumbuh dari bibit single bud yang relatif tinggi di bandingkan dengan cara konvemsional.

\section{Alih}

teknologi

pengetahuan

penggunaan alat pemotong bagal tebu dengan mesin pemotong.

Pada tahap yang kedua ini di berikan alih teknologi terkait dengan alat atau mesin pemotong bagal dengan menggunakan mesin pemotong, keuntungan dan kelebihan dari alat tersebut serta teknis cara penggunaannnya.

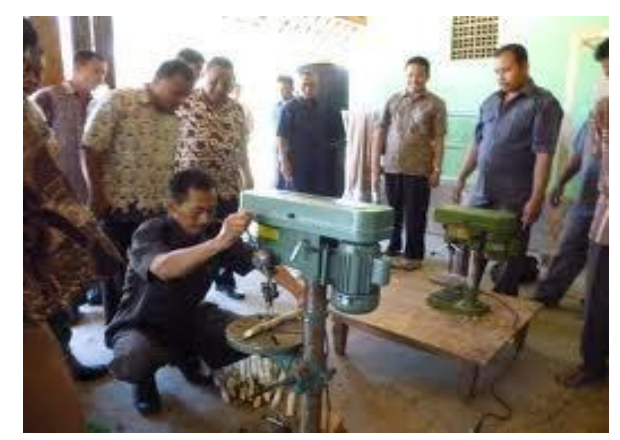

Gambar 3.1 Alat Bor Mata Tunas Single Bud

$$
\text { Planting }
$$

3. Alih teknologi pengetahuan terkait pengembangan usaha dari pembibitan tebu dengan metode single bud planting.

Pada tahap yang ke tiga ini diberikan alih teknologi terkait dengan prospek

pengembangan pembibitan tebu di lihat dari sudut pandang ekonomi di bandingkan dengan pengembangan dengan cara konvensional.

\section{Praktek Pelaksanaan Metode Single Bud palnting dan Uji Coba alat Bor Single Bud Planting.}

Agar pemahaman mitra lebih terasah dan tidak hanya di bayangkan terkait metode single bud planting maka dengan praktek langsung diharapkan akan lebih terampil dalam melaksanakan kegiatan pembibiitan tebu dengan metode single bud palnting. Serta pengguanaan alat bor yang baik dan benar sehingga di peroleh mata tunas yang berkualitas sebagai bahan tanam dari pembibitan single bud planting.

\section{Evaluasi}

Evaluasi hasil yang di lakukan dengancara meninjau langsung pada para petani yang sudah melaksanakan metode single bud planting dalam pengembangan usaha pembibitan tebu, serta melakukan diskusi dan tanya jawab secara langsung denganpara petani pengembang bibit tebu maupun petani produksi. Selama berlangsung kegiatan IbM tim pelaksana pengabdian selalu memantau atau memonitoring dan bertanggung jawab terhadap pelaksanaan kegiatan pengabdian ini. Untuk selanjutnya di jalin kerja sama antara mitra yaitu petani pengembang bibit dan petani produksi tebu di Kecamatan Semboro dengan

Kerangka pemecahan masalah program Pengembangan Pembibitan tebu dengan metode Single bud planting adalah sebagai berikut:

(SEBELUM PROGRAM IbM)

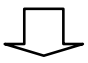

Pengembangan Pembibitan Tebu dengan

Cara konvensional

(Dibutuhkan waktu lama dan biaya tinggi)

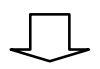

Hasil Bibit yang di peroleh terbatas, tidak seragam dan daya tumbuh bibit relatif rendah

(Keuntungan kecil dan terkadang rugi) 
(SESUDAH PROGRAM IbM)

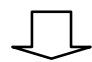

Pengembangan Pembibitan Tebu dengan cara Single Bud Planting

(Waktu lebih singkat dan biaya relatif rendah)

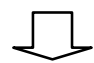

Hasil bibit yang di peroleh lebih banyak, lebih seragam dan daya tumbuh bibit relatif tinggi

(Keuntungan lebih besar)

\section{HASIL YANG DICAPAI}

\subsection{Sosialisasi dan Kordinasi Kegiatan IbM} Kegiatan pengabdian Ipteks Bagi Masyarakat (IbM) diawali dengan sosialisasi dan koordinasi dengan mitra IbM yang dilaksanakan pada awal bulan April 2014, agenda utama kegiatan ini adalah terkait rencana pelaksanaaan kegiatan IbM kelompok petani tebu rakyat dikecamatan Semboro. Pada tahap kegiatan ini banyak diterangkan jadwal rencana kegiatan mulai dari pelatihan penggunaan mesin alat bor hingga teknis pelaksanaan sistem budidaya single bud planting, sehingga bisa menetapkan waktu yang sesuai antara tim pelaksana IbM dengan mitra. Hasil dari kegiatan awal ini adalah rencana kegiatan dan waktu telah disepakati antara tim pelaksana dengan mitra untuk setiap tahap pelaksanaan kegiatan pengabdian.

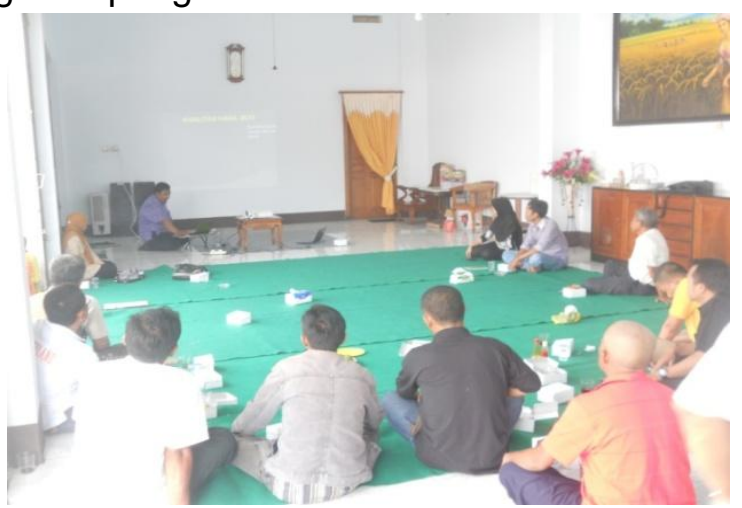

Gambar 4.1 Sosialisasi dan kordinasi rencana kegiatan IbM

Sosialisasi kegiatan ini juga bertujuan untuk memberikan gambaran umum terkait pola pembibitan single bud dan pola budidayanya dilahan produksi serta tekhnis penyiapan pembibitan single bud.

Kegiatan pengabdian ini sedianya akan dilaksanakan sesuai dengan jadwal yang telah di tetapkan antara tim pelaksana IbM dengan mitra IbM yaitu mulai bulan April 2014 hingga September 2014 yang akan dilanjutkan dengan evaluasi dari seluruh kegiatan pada bulan Nopember.

\subsection{Pengenalan Perangkat Alat Bor Pemotong Bibit Tebu}

Salah satu alat yang penting dalam pembibitan tebu dengan metode single bud adalah alat bor. Alat bor ini digunakan untuk memotong bagal-bagal tebu menjadi satu mata tunas sebagai bahan tanam di pembibitan PI (Persemaian I), dalam kegiatan ini di terangkan bahwa selain menggunakan alat pemotong manual berupa parang ataupun gergaji maka alat bor adalah alat yang paling efisien dan efektif baik secara tenaga, biaya dan waktu dalam hal tekhnis pemotongan bahan tanam single bud, oleh karena itu dalam agenda kegiatan kedua ini tim pelaksana $\mathrm{lbm}$ banyak menerangkan terkait alat bor tersebut.

Alat bor yang di gunakan adalah alat bor duduk, yang harus di modifikasi sedemikian rupa baik di mata bor nya maupun bagian alas bor (pangkon), sehingga bisa sesuai untuk digunakan memotong bahan tanam tebu single bud.

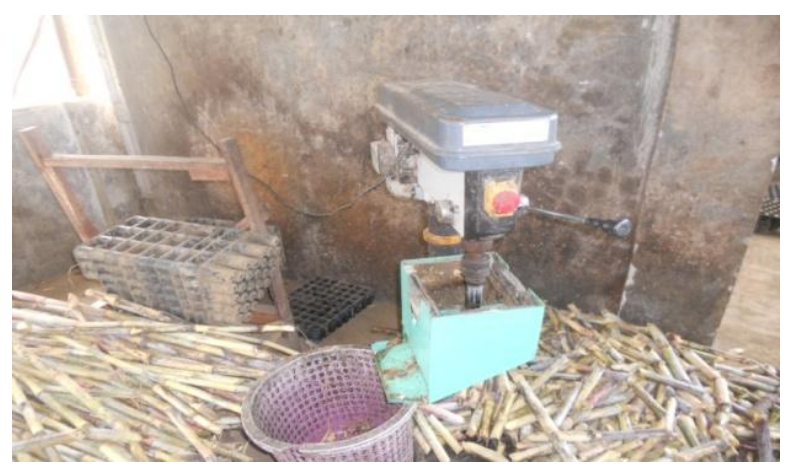

Gambar 4.2 Alat bor single bud

Gambar 4.2 memperlihatkan bahwa mata bor dan alas bor sudah dimodifikasi sehingga sesuai untuk memotong mata tunas tebu yang digunakan sebagai bahan tanam dalam pembibitan single bud. 


\subsection{Pelatihan Modifikasi Pemasangan Perangkat Alat Bor Single Bud}

Pada tahap kegiatan ini, mitra IbM diberikan pengetahuan terkait tekhnis pemasangan mata bor dan alas bor serta pemeliharaan alat sehingga mitra menjadi paham untuk penggunaan alat bor secara baik dan benar, Mata bor yang digunakan berbentuk bulat sehingga bisa memotong mata tunas secara sempurna sehingga tidak mempengaruhi daya tumbuh dari bahan tanam yang dihasilkan. Mitra Ibm juga cukup interaktif dalam mengikuti kegiatan ini sehingga banyak pertanyaan yang diajukan kepada tim pelaksana terkait alternatif disain mata bor. Alas bor (pangkon) didisain sedemikian rupa sehingga mata tunas dari bahan tanam tebu yang telah dipotong bisa langsung mengarah bak penampungan, sehingga bahan tanam lebih higienis dan meminimalisir menempelnya bahan yang tidak diinginkan ke bahan tanam yang telah dipotong.

Pemeliharaan alat juga menjadi salah satu sasaran dari materi kegiatan tahap ini di mana alat bor yang tidak dilakukan pemeliharaan akan sangat rawan terjadi kerusakan sehingga dapat memperpendek masa guna dari alat tersebut. Beberapa pemeliharaan alat yang perlu untuk dilakukan adalah kebersihan alat, ketajaman mata bor serta pelumas oli yang diberikan di mesin bor agar mesin terus dapat digunakan dalam jangka panjang.

\subsection{Pengenalan Perangkat alat Hot Water Treatment (HWT)}

Alat Hot Water Treatment (HWT) adalah salah satu alat yang digunakan dalam rangkaian proses single bud planting alat ini berfungsi sebagai alat sterilisasi dari bahan tanam tunas tebu yang telah dipotong sehingga bahan tanam yang dihasilkan terbebas dari bibit penyakit yang menempel pada tunas tebu tersebut, alat HWT ini dapat menggunakan alat yang paling sederhana hingga menggunakan alat yang sudah dilengkapi dengan mesin pengatur suhu secara otomatis.

\subsection{Pelatihan Persiapan Lahan Persemaian I}

Lahan persemaian dalam pola pembibitan single bud planting adalah mutlak di perlukan oleh karena itu pada tahap kegiatan ini tim pelaksana lbM memberikan pelatihan terkait persiapan apa saja yang harus dilakukan dalam lahan persemaian tahap I, lahan persemaian dianjurkan pada lahan terbuka yang cukup terkena sinar matahari dan jauh dari pepohonan yang bisa menghalangi masuknya sinar matahari, agar proses perkecambahan bibit bisa berlangsung secara optimal, mitra di berikan pelatihan juga terkait ukuran lahan persemaian yang standar dan bentuk dari lahan bedengan yang digunakan sebagai tempat persemaian I. Pada tahap kegiatan ini mitra lbm praktek langsung membuat bedengan untuk persiapan persemain I.

\subsection{Praktek Penggunaan Alat Bor Pemotong Mata Tunas Tebu.}

Setelah mitra diberikan pengetahuan terkait alat bor, alat HWT dan persiapan lahan persemaian maka tahap selanjutnya adalah praktek penggunaan alat bor pemotong mata tunas tebu. Penggunaan alat bor relative mudah sehingga mitra lbM tidak banyak mengalami kesulitan hanya perlu sering menggunakan maka kecepatan kerjanya akan lebih trampil dan cepat.

Setelah mata tunas tebu yang akan digunakan terpotong semua maka bahan tanam tersebut dilakukan proses HWT selama kurang lebih $10-15$ menit dengan suhu sekitar 40 - 500C, setelah itu di masukan diwadah baky yang berisi air dingin yang sudah dicampur dengan fungisida dan ZPT, setelah tahap ini dilakukan maka bahan tanam siap di tanam di bedengan persemaian I. 


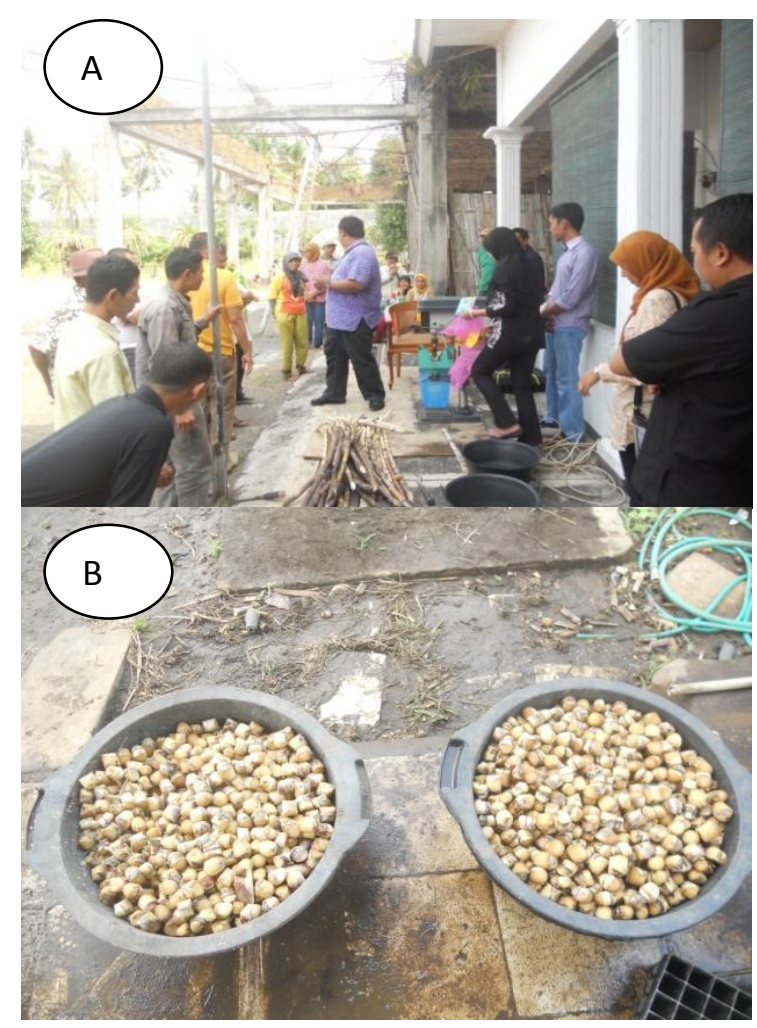

Gambar 4.3 Praktek pemotongan mata tunas tebu (A) dan Hasil pemotongan mata tunas setelah perlakuan HWT (B).

Praktek selanjutnya yang dilakukan adalah praktekteknis penanaman dimana jarak tanam harus sesuaidan ditanam secara rapi sesuai dengan jarak tanam yang telah ditentukan dengan posisi mata tunas di atas dan bagian tunas ditutup dengan tanah tipis.

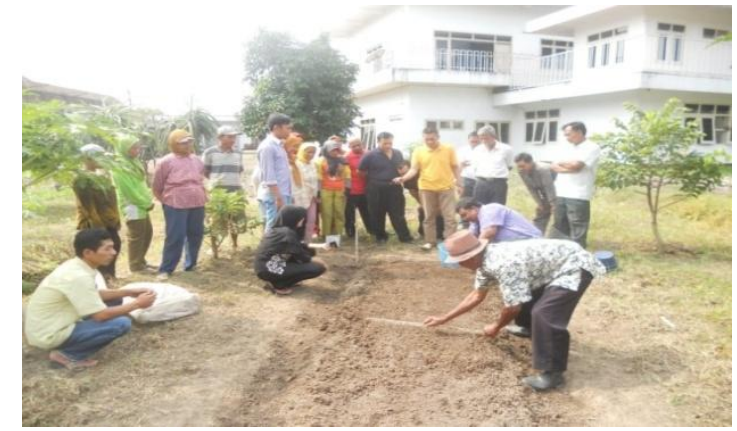

Gambar 4.4 Penanaman mata tunas tebu single bud di persemaian tahap I

\subsection{Pemeliharaan Pembibitan di Persemaian Tahap I}

Pemeliharan adalah wajib dilakukan maka pada kegiatan tahap ini mitra IbM turut aktif melaksanakan pemeliharaan terhadap bibit tebu yang disemaikan pada persemaian I $(\mathrm{PI})$, pemeliharaan yang dilakukan adalah melakukan penyiramaan dan membersihkan gulma yang tumbuh di sekitar tanaman.

\subsection{Persiapan Pemindahan bibit Persemaian I ke Persemain II}

Pada tahap kegiatan ini mitra di berikan pengetahuan terkait pemindahan bibit hasil persemain I ke persemaian II, bibit tebu hasil persemaian I baru bisa di pindah ke persemaian II setelah berumur kurang lebih 14 hari. Setelah 14 hari bibit di p[indah ke potray dan hal penting yang perludi perhatikan adalah tekhnis pemindahan bibit harus hati hati, dengan menggunakan alat serok ataupun sekop dan jangan sampai merusak perakaran dari bibit tersebut. Sebelum di pindah ke P II maka terlebih dahulu menyiapkan media bahan tanam di potray dan potray tersebut di isi dengan media tanah + kompos dengan perbandingan 1:1, setelah media P II siap maka potray diisi dengan media kurang lebih nya separo dari tinggi potray kemudian bibit hasil dari P I dipindah ke Potray baru setelah itu potray disi dengan media lagi sampai penuh.

\subsection{Pemindahan Bibit P I ke PII}

Setelah mitra memahami tehnis pemindahan bibit P I ke P II maka pada tahap kegiatan ini mitra praktek langsung memindah bibit P I ke P II, hasil dari kegiatan ini mitar semakin paham terkait pola dan tekhnis pembibitan single bud planting.

\subsection{Pelatihan Persiapan Lahan Produksi Budidaya Bibit SBP}

Sebelum bibit tebu tahap $P$ Ildi panen maka mitra di berikan pengetahuan terkait pola tanam lahan produksi bibit SBP, pola tanam dari bibit SBP jauh berbeda dengan system bagal atau rayungan. Untuk pengolahan tanah sama dengan system bagal atau rayungan yaitu dengan system reynoso, namun untuk penanaman teknisnya yaitu harus membuat lubang tanam terlebih dahulu disesuaikan dengan jarak tanam yang sudahdi tentukan, ssetelah itu baru bibit hasil P II bisa di tanam di lahan produksi. Syarat bibit P II yang layak di pindah ke lahan produksi adalah bibit harus dalam kondisi 
sehat terbebas dari serangan hama dan penyakit dan kurang lebih di potray telah berumur 2,5 bulan.

\subsection{Pemeliharaan Bibit Tebu SBP di P II}

Pemeliharaan di persemaian tahap II(PII) adalah penting dilakukan maka mitra juga ikut berperan aktif untuk melakukan pemeliharaan yaitu dengan rutin melakukan penyiraman dan mengendalikan organisme penganggu tanaman, baik berupa hamamaupun penyakit.

\section{SARAN DAN KESIMPULAN}

Dari hasil kegiatan yangtelah dilaksanakan maka dapat di tarik beberapa saran dan kesimpulan sebagai berikut:

\section{Saran}

1. Perlu ditingkatkan lagi kerjasama lebih lanjut dengan mitra mengingat potensi pengembangan usaha pembibitan masih terbuka luas.

2. Perlu dilakukan variasi teknologi alat yang lebih canggih untuk meningkatkan kinerja dan produksi pembibitan single bud.

\section{Kesimpulan}

1. Kegiatan IbM mono tahun dilaksanakan dengan lancar dan peran aktif mitra cukup tinggi dalam setiap tahap kegiatan.

2. Transfer teknologi pembibitan tebu dengan metode single bud banyak memeberikan ilmu dan pengetahuan baru bagi mitra mengingat teknologi ini masih jarang dilakukan oleh mitra.

\section{DAFTAR PUSTAKA}

PTPN XI,. 20I3. Tekhnik Budidaya Tebu, PabrikGula Sembor, Jember

PTPN XI, 2012. Buku Panduan Tekhnis Pelaksanaan Pembibitan Single Bud, Pabrik Gula Semboro, jember

R.M. Edhi Sutardjo, 1994, Budidaya Tanaman Tebu,Bumi Aksara, Jakarta 